\title{
SUBJEK HUKUM RAHASIA DAGANG DITINJAU DARI UNDANG-UNDANG RAHASIA DAGANG, TRIPS AGREEMENT DAN UTSA*
}

Oleh:

Regina Natalie Theixar ${ }^{* *}$

I Gusti Ngurah Wairocana***

Program Kekhususan Hukum Bisnis Fakultas Hukum

Universitas Udayana

\begin{abstract}
ABSTRAK
Rahasia Dagang atau informasi yang dirahasiakan merupakan salah satu hak kekayaan intelektual yang dimiliki oleh sejumlah besar pedagang dengan ide kreatif dalam menjalankan usahanya. Namun, hukum yang mengatur mengenai Rahasia Dagang di Indonesia ternyata tidak memberikan deskripsi yang jelas mengenai subjek hukum. Tujuan dari penulisan jurnal ilmiah ini adalah untuk lebih memahami siapa yang berhak menjadi subjek hukum yang sah menurut Undang-Undang Rahasia Dagang. Metode penelitian yang digunakan adalah penelitian hukum normatif dengan pendekatan perundang-undangan dan pendekatan komparatif. Sumber bahan hukum yang digunakan berupa bahan hukum primer, sekunder, dan tersier. Untuk menghindari kekosongan hukum, Indonesia memerlukan perubahan Undang-Undang yang mengatur mengenai subjek hukum Rahasia Dagang yaitu perseorangan dan badan hukum, sebagai negara yang telah meratifikasi Persetujuan TRIPs.
\end{abstract}

Kata Kunci : Rahasia Dagang, Informasi, Subjek Hukum.

\begin{abstract}
Trade Secret or undisclosed information is one of the intellectual property rights that is owned by a large number of traders with creative ideas on running their business. However, Indonesia does not provide a clear description about the legal subject of Trade Secrets's law. The purpose of writing this scientific journal is to understand better about who is entitled to be a legitimate legal subject under the Trade Secrets Act. The research

\footnotetext{
* Tulisan ini diluar skripsi bersama Pembimbing Akademik sebagai penulis kedua.

** Regina Natalie Theixar adalah Mahasiswa Fakultas Hukum Universitas Udayana, reginatheixar@gmail.com

*** I Gusti Ngurah Wairocana adalah Dosen Pengajar Hukum Administrasi Negara Fakultas Hukum Universitas Udayana
} 
method used is normative legal research with the statute approach and comparative approach. The source of legal materials used are primary, secondary, and tertiary legal materials. To avoid legal vacuum, Indonesia needs to amend its act that governs the legal subject of Trade Secret Law which are natural and legal persons, as a country that have ratified TRIPs Agreement.

Keywords: Trade Secret, Information, Legal Subject.

\section{PENDAHULUAN}

\subsection{Latar Belakang}

Perdagangan telah menjadi salah satu unsur penting dalam kehidupan manusia untuk saling memenuhi kebutuhan satu sama lain. Dalam era globalisasi ini, persaingan dalam berdagang menjadi semakin ketat karena pertumbuhan ekonomi yang pesat. Setiap pedagang saling berlomba untuk berinovasi agar memiliki ciri khasnya masing-masing. Kekhasan dari suatu teknologi atau bisnis yang mempunyai nilai jual, dijaga agar tidak diketahui oleh publik. Ciri khas inilah yang tidak diketahui umum disebut dengan Rahasia Dagang.

Rahasia Dagang sudah merupakan hal yang lazim dalam dunia usaha. Permasalahan kerahasiaan yang berhubungan dengan rahasia perusahaan, telah memperoleh perhatian oleh Pengadilan sejak awal abad kesembilan belas. ${ }^{1}$ Suatu informasi atau data yang bersifat rahasia merupakan hal yang sangat penting bagi dunia usaha. Kerahasiaan itu sendiri pada dasarnya bersifat relatif, dan tidak absolut. Suatu informasi yang bersifat rahasia berarti tidak terbuka untuk umum, orang luar, dan bersifat tidak rahasia bagi para pihak yang terlibat secara langsung dengan keberadaan dan pemanfaatan informasi itu

1 Gunawan Widjaja, 2001, Rahasia Dagang, PT RajaGrafindo Persada, Jakarta, h. 1. 
sendiri. ${ }^{2}$ Sebuah rahasia dagang tidak ada batas waktu perlindungan selama pemiliknya menjaga rahasia dagangnya dari akses publik, selama itu pula rahasia dagangnya terlindungi. Rahasia Dagang tidak mengatur mengenai persyaratan pendaftaran sehingga perlindungan hukum dapat diperoleh segera bagi mereka yang memiliki rahasia dagang. ${ }^{3}$

Indonesia sebagai negara yang telah meratifikasi Agreement Establishing the World Trade Organization (Persetujuan Pembentukan Organisasi Perdagangan Dunia) yang mencakup di dalamnya Agreement on Trade Related Aspects of Intellectual Property Rights (Persetujuan TRIPs) dengan Undang-Undang Nomor 7 Tahun 1994, pada akhirnya dapat merealisasikan pengakuan akan rahasia dagang pada tanggal 20 Desember 2000 dengan diundangkannya Undang-Undang Republik Indonesia Nomor 30 Tahun 2000 tentang Rahasia Dagang (selanjutnya akan disebut Undang-Undang Rahasia Dagang). Undang-Undang ini dibuat dengan tujuan untuk memajukan industri nasional yang nantinya akan mampu bersaing dalam lingkup perdagangan internasional. Dengan ini berarti Indonesia telah membuka pintu bagi masuknya globalisasi perdagangan yang diikuti dengan proses pemberadaban (civilization) aturan-aturan main perekonomian dan perdagangan dunia ke Indonesia, termasuk TRIPs, Kekayaan Intelektual dan Rahasia Dagang. ${ }^{4}$

Pengertian mengenai Rahasia Dagang diatur dengan jelas dalam Pasal 1 angka 1 Undang-Undang Rahasia Dagang, yang berbunyi: "Rahasia Dagang adalah informasi yang tidak diketahui oleh umum di bidang teknologi dan/atau bisnis, mempunyai nilai

${ }^{2}$ Ibid, h. 3.

${ }^{3}$ Indira Swasti Gama Bhakti, "Rahasia Dagang dalam Usaha Franchise di Bidang Kuliner", Jurnal Fakultas Ilmu Sosial dan Ilmu Politik Universitas Tidar, Vol. 1, No.1, 2017, Magelang.

${ }^{4}$ Gunawan Widjaja, op.cit, h. 6. 
ekonomi karena berguna dalam kegiatan usaha, dan dijaga kerahasiaannya oleh pemilik Rahasia Dagang."

Undang-Undang Rahasia Dagang hanya terdiri dari 19 pasal dan memuat aturan yang sangat singkat. Oleh karena itu, banyak ditemukan norma kosong. Salah satunya yaitu siapakah subjek hukum dalam Rahasia Dagang di Indonesia, apakah hanya orangperorangan atau dapatkah badan hukum juga menjadi subjek hukum Rahasia Dagang jika dikaitkan dengan Pasal 4 huruf a Undang-Undang Rahasia Dagang yang secara implisit menyatakan orang (naturlijke person) adalah subjek hukum rahasia dagang di Indonesia, dan bagaimana perbandingannya dengan TRIPs Agreement yang telah diratifikasi oleh Indonesia serta Uniform Trade Secret Act with 1985 Amendments (UTSA) yang merupakan Undang-Undang Amerika Serikat mengenai rahasia dagang. Sebagai salah satu negara yang meratifikasi TRIPs Agreement, sudah selayaknya Indonesia turut serta mengatur mengenai kedudukan badan hukum selaku subjek hukum rahasia dagang. Berdasarkan hal tersebut, penulis akan mengkaji analisa yang berjudul "SUBJEK HUKUM RAHASIA DAGANG DITINJAU DARI UNDANG-UNDANG RAHASIA DAGANG, TRIPS AGREEMENT DAN UTSA".

\subsection{Rumusan Masalah}

Dengan adanya latar belakang tersebut, maka adapun rumusan masalah yang menurut penulis patut di angkat adalah :

1. Siapakah sebagai subjek hukum rahasia dagang menurut Undang-Undang Rahasia Dagang?

2. Bagaimanakah pengaturan subjek hukum antara UndangUndang Rahasia Dagang dengan TRIPs Agreement? 
3. Bagaimanakah pengaturan subjek hukum antara UndangUndang Rahasia Dagang dengan Uniform Trade Secret Act with 1985 Amendments (UTSA)?

\subsection{Tujuan}

Tujuan penulisan jurnal ilmiah ini dimaksudkan untuk lebih memahami siapa yang berhak menjadi subjek hukum yang sah menurut Undang-Undang Rahasia Dagang.

\section{ISI MAKALAH}

\subsection{Metode Penelitian}

\subsubsection{Jenis penelitian}

Penulis menggunakan penelitian normatif dalam membuat jurnal ilmiah ini. Penelitian hukum normatif merupakan suatu bentuk penulisan hukum untuk kepentingan akademik yang mendasarkan pada karakteristik Ilmu Hukum sebagai ilmu sui generis atau ilmu yang memiliki kepribadian khas, sebagai berikut ${ }^{5}$ : (a) Karakter normatif ilmu hukum; (b) Terminologi ilmu hukum; (c) Jenis ilmu hukum; (d) Lapisan ilmu hukum.

\subsubsection{Jenis pendekatan}

Pada penulisan jurnal ilmiah ini diperggunakan pendekatan perundang-undangan dan pendekatan komparatif. Pendekatan perundang-undangan adalah pendekatan yang meneliti aturanaturan yang berkaitan dengan isu hukum yang relevan dengan topik yang dibahas. Sedangkan pendekatan komparatif yaitu membandingkan Undang-Undang suatu negara, dengan Undang-

5 Asri Wijayanti dan Lilik Sofyan Achmad, 2011, Strategi Penulisan Hukum, CV. Lubuk Agung, Bandung, h. 43. 
Undang dari satu atau lebih negara lain mengenai perihal yang sama. 6

\subsubsection{Bahan hukum}

Berikut bahan hukum yang dipergunakan dalam jurnal ilmiah ini yaitu :

1. Bahan hukum primer yang terdiri dari bahan hukum yang mengikat yaitu UUD NRI 1945, TRIPs Agreement dan Undang-Undang Rahasia Dagang.

2. Bahan hukum sekunder, yaitu bahan hukum yang memberi penjelasan terhadap bahan hukum primer, seperti misalnya buku-buku hukum, hasil penelitian, hasil karya dari pakar hukum, dan lain sebagainya.

3. Bahan hukum tersier memberikan penjelasan terhadap bahan hukum primer dan sekunder, contohnya adalah ensiklopedi hukum dan kamus hukum. ${ }^{7}$

\subsubsection{Teknik pengumpulan bahan hukum}

Teknik pengumpulan bahan hukum dalam jurnal yang menggunakan penelitian hukum normatif dilakukan dengan studi kepustakaan yang berkaitan dengan permasalahan dan bahan hukum dengan menafsirkan dan mengkaji peraturan perundangundangan. Langkah-langkah yang dapat ditempuh yaitu mengumpulkan bahan-bahan terkait permasalahan untuk kemudian dikutip bagian-bagian yang relevan dengan topik yang diangkat kemudian disusun secara sistematis sesuai dengan pembahasan dalam penelitian ini.

${ }^{6}$ Peter Mahmud Marzuki, 2011, Penelitian Hukum, Edisi Revisi, Kencana Prenada Media Group, Jakarta, h. 95.

7 Zainuddin Ali, 2016, Metode Penelitian Hukum, Cet.VII, Sinar Grafika, Jakarta, h. 24. 


\subsubsection{Teknik analisis bahan hukum}

Pada penelitian hukum normatif ini, teknik analisis bahan hukum yang digunakan oleh penulis adalah teknik deskripsi, teknik interpretasi dan teknik sistematisasi. Teknik deskripsi yaitu menguraikan posisi atau kondisi dari berbagai proposisi hukum maupun proposisi non hukum. Teknik interpretasi adalah penggunaan jenis-jenis penafsiran dalam ilmu hukum berupa penafsiran grammatikal, sistimatis, dan lain-lain. Teknik sistematisasi adalah upaya mencari keterkaitan rumusan suatu peraturan perundang-undangan yang sederajat atau setara maupun tidak sederajat.

\subsection{Hasil Analisa}

\subsubsection{Subjek hukum rahasia dagang menurut Undang-Undang Rahasia Dagang}

Subjek hukum adalah sesuatu yang menurut hukum berhak atau berwenang untuk melakukan perbuatan hukum atau siapa yang mempunyai hak dan cakap untuk bertindak dalam hukum. Subjek hukum terdiri dari natuurlijk person yaitu orang atau manusia pribadi dan rechtsperson yang berbentuk badan hukum. ${ }^{8}$

Hukum yang mengatur mengenai rahasia dagang adalah Undang-Undang Republik Indonesia Nomor 30 Tahun 2000 tentang Rahasia Dagang. Undang-Undang ini hanya terdiri dari 19 pasal, yang tidak ada satu pun dari pasal tersebut yang membahas secara eksplisit mengenai siapa subjek hukum rahasia dagang. Pasal 4 Undang-Undang Rahasia Dagang mengatur mengenai hak pemilik rahasia dagang, yaitu hak untuk menggunakan Rahasia Dagang yang dimilikinya itu untuk dirinya sendiri dan hak untuk memberikan lisensi serta hak untuk

8 R. Soeroso, 2015, Pengantar Ilmu Hukum, Cet. XV, Sinar Grafika, Jakarta, h. 228. 
melarang pihak-pihak lain untuk menggunakan maupun mengungkapkan Rahasia Dagang itu kepada pihak ketiga demi kepentingan ekonomi yang bersifat komersial. Pasal 11 ayat (1) mengatur mengenai penyelesaian sengketa antara pemegang hak rahasia dagang dengan siapapun yang tanpa hak dan dengan sengaja menggunakan atau mengungkapkan Rahasia Dagang kepada pihak lain demi kepentingan ekonomi.

Dari rumusan pasal-pasal tersebut, timbullah pertanyaan, siapa yang disebut pemilik rahasia dagang dan siapa yang disebut pemegang rahasia dagang. Pemilik rahasia dagang adalah orang yang memiliki dan menjaga kerahasiaan informasi yang mempunyai nilai ekonomi di bidang teknologi dan/atau bisnis karena informasi tersebut berguna dalam kegiatan usahanya. ${ }^{9}$ Jika dihubungkan dengan pasal 5 ayat (1) yang mengatur mengenai pengalihan hak rahasia dagang, maka dapat dikatakan bahwa Pemilik Rahasia Dagang adalah penemu atau originator dari informasi-informasi yang dirahasiakan tersebut, yang disebut dengan Rahasia Dagang. Sedangkan Pemegang Rahasia Dagang adalah Pemilik Rahasia Dagang dan pihak-pihak yang memperoleh hak lebih lanjut dari Pemilik Rahasia Dagang, yang terjadi sebagai akibat berlakunya ketentuan pasal 5 ayat (1) Undang-Undang Rahasia Dagang. ${ }^{10}$

Tidak ada pembahasan eksplisit mengenai siapa subjek hukum rahasia dagang baik dalam literatur maupun UndangUndang. Namun, jika dilihat dari pernyataan sarjana, Yusran Isnaini (2010:98), "Seseorang dapat secara langsung atau otomatis mendapatkan hak atas rahasia dagang atau tanpa perlu melalui pendaftaran, karena hak tersebut timbul berdasarkan undangundang" dan Pasal 4 huruf a Undang-Undang Rahasia Dagang,

9 Yusran Isnaini, 2010, Buku Pintar HAKI, Ghalia Indonesia, Bogor, h. 98

10 Gunawan Widjaja, op.cit, h. 85. 
"Pemilik rahasia dagang memiliki hak untuk menggunakan sendiri Rahasia Dagang yang dimilikinya", maka penulis menafsirkan bahwa hukum Indonesia hanya mengenal perorangan (natuurlijk person) sebagai subjek Rahasia Dagang.

\subsubsection{Pengaturan subjek hukum antara Undang-Undang Rahasia Dagang dengan TRIPs Agreement}

Perlindungan akan informasi yang dirahasiakan hanya diatur oleh satu pasal saja dalam lampiran 1C Agreement Establishing The World Trade Organization (the Agreement on Trade Related Aspect of Intellectual Property Rights, including Trade in Counterfeit Goods), yaitu pada pasal 39 Bagian 7 tentang Protection of Undisclosed Information.

Pada intinya, Pasal 39 ayat (1) TRIPs diadakan dengan tujuan untuk menjamin efektivitas pelaksanaan perlindungan atas persaingan usaha tidak sehat, yang diatur dalam Pasal 10 bis Paris Convention (1967). Untuk menjamin pelaksanaan perlindungan atas persaingan usaha tidak sehat ini maka para anggota WTO diwajibkan untuk melindungi informasi yang dirahasiakan tersebut, maupun atas data-data yang diserahkan kepada pemerintah atau agen pemerintah.

Pasal 39 ayat (2) TRIPs mengatur mengenai hak bagi orang perorangan ataupun badan atas perlindungan terhadap informasi yang ada pada diri mereka, yang tidak diungkapkan oleh mereka, yang diperoleh atau dipergunakan oleh pihak lain secara tidak sah atau tidak jujur tanpa persetujuannya menurut cara yang bertentangan dengan praktek usaha yang jujur, selama dan sepanjang:

1. informasi tersebut memang bersifat rahasia, dengan pengertian bahwa informasi tersebut bukanlah sesuatu yang 
dapat dengan mudah diketahui oleh orang dalam suatu rangkaian kegiatan yang berhubungan dengan informasi rahasia yang dipersoalkan;

2. memiliki nilai komersial karena kerahasiaannya;

3. pihak yang memiliki informasi rahasia tersebut telah mengambil upaya yang wajar untuk melindungi informasi tersebut dari keterbukaan.

Sedangkan ketentuan Pasal 39 ayat (3) berhubungan dengan masalah pengungkapan informasi rahasia yang diharuskan untuk disampaikan kepada Pemerintah atau agen pemerintah sehubungan dengan izin perdagangan produk farmasi atau pertanian. Dalam hal demikian maka negara anggota WTO harus memberikan perlindungan atas informasi rahasia yang disampaikan tersebut di praktek perdagangan tidak sehat. ${ }^{11}$

Dari penjelasan pasal diatas, dapat dilihat bahwa tidak banyak pengaturan mengenai rahasia dagang di TRIPs Agreement, satu-satunya ayat yang membahas paling detil mengenai rahasia dagang adalah ayat (2). Jika ditelaah dari rumusan ayat tersebut, maka dapat ditemukan bahwa subjek rahasia dagang adalah natural and legal persons (individu dan badan hukum).

Indonesia sebagai salah satu negara anggota TRIPs yang telah meratifikasi perjanjian tersebut, mengesahkan UndangUndang Rahasia Dagang pada tahun 2000. Menurut kamus hukum, Ratifikasi atau Ratificatio dalam bahasa Latin adalah pengesahan satu perjanjian antara negara atau internasional menjadi Undang-Undang; pernyataan resmi negara untuk diikat ketentuan-ketentuan traktat. Dalam hal ini, Indonesia memiliki keterikatan untuk mengikuti substansi dari Persetujuan TRIPs, namun dalam Undang-Undang Rahasia Dagang, pengaturan

${ }^{11}$ Ibid, h. 25. 
mengenai subjek hukum tidak dicantumkan, sehingga menyebabkan kekosongan hukum.

\subsubsection{Pengaturan subjek hukum antara Undang-Undang Rahasia Dagang dengan Uniform Trade Secret Act with 1985 Amendments (UTSA)}

Pada 2 hingga 9 Agustus 1985, diadakan Annual Conference Meeting di Minneapolis, Minnesota yang menghasilkan Uniform Trade Secret Act with 1985 Amendments (UTSA) yang diusulkan untuk dipergunakan secara seragam di seluruh negara bagian di Amerika Serikat. UTSA ini hanya terdiri dari 12 Sections, pengertian dasar dalam Section I yaitu pada ayat (3), yang menyatakan bahwa: "pihak (person) yang diartikan secara luas meliputi tidak hanya orang perorangan, melainkan juga perusahaan, unit usaha, estat, persekutuan, perkumpulan, kerja sama, pemerintah, agen, dan badan-badan usaha lainnya."12

Terjemahan ayat di atas secara eksplisit menyatakan bahwa yang merupakan subjek hukum dari rahasia dagang tidak hanya meliputi orang perorangan (natuurlijke person), namun juga meliputi perusahaan, unit usaha, estat, dan sebagainya yang merupakan bagian dari badan hukum (rechtsperson).

Amerika Serikat merupakan salah satu negara anggota World Trade Organization (WTO) sejak 1 Januari 1995. Seluruh anggota WTO yang tercatat, meratifikasi TRIPs Agreement. Amerika Serikat resmi meratifikasi TRIPs Agreement pada tanggal 17 Desember 2005. Indonesia dan Amerika Serikat sama-sama merupakan anggota WTO dan meratifikasi TRIPs Agreement, sehingga dapat dilihat perbandingan antara produk hukum yang diciptakan Indonesia dan Amerika terkait dengan Rahasia Dagang.

12 Ibid, h. 33. 
Sebagai negara anggota yang telah meratifikasi TRIPs Agreement, Amerika Serikat telah memiliki aturan yang berkesinambungan dan mendefinisikan secara detil mengenai subjek hukum yang memiliki hak kepemilikan rahasia dagang.

\section{PENUTUP}

\subsection{Kesimpulan}

1. Indonesia tidak mengatur secara tegas mengenai subjek Rahasia Dagang di Undang-Undang Rahasia Dagang, namun menurut pernyataan sarjana dan penafsiran penulis mengenai pasal 4 huruf a Undang-Undang Rahasia Dagang, Indonesia hanya mengakui orang perorangan (natuurlijke person) sebagai subjek hukum Rahasia Dagang.

2. TRIPs Agreement mengakui orang perorangan (natuurlijke person) dan badan hukum (rechtsperson) sebagai subjek hukum Rahasia Dagang sebagaimana diatur dalam Pasal 39 ayat (2) Bagian 7 tentang Protection of Undisclosed Information lampiran 1C TRIPs Agreement. Sehingga Indonesia yang merupakan negara anggota TRIPs Agreement sudah seharusnya turut serta mengatur mengenai subjek hukum Rahasia Dagang di peraturan perundang-undangannya.

3. Secara eksplisit dalam Section $I$ ayat (3) UTSA dicantumkan bahwa subjek hukum atau pihak yang diakui dalam UTSA bukan hanya orang perorangan, namun juga perusahaan, unit usaha, estat, persekutuan, perkumpulan, kerja sama, pemerintah, agen, dan badanbadan usaha lainnya, yang merupakan bagian dari rechtsperson. 


\subsection{Saran}

Indonesia sebagai negara yang telah meratifikasi TRIPs Agreement seyogyanya turut serta mengatur mengenai subjek hukum rahasia dagang dengan jelas dalam peraturan perundangundangannya yakni Undang-Undang Rahasia Dagang, sama seperti Amerika Serikat dalam UTSA, yang juga telah meratifikasi TRIPs Agreement.

\section{DAFTAR PUSTAKA}

\section{Buku}

Marzuki, Peter Mahmud, 2011, Penelitian Hukum, Edisi Revisi, Kencana Prenada Media Group, Jakarta.

R. Soeroso, 2015, Pengantar Ilmu Hukum, Cet. XV, Sinar Grafika, Jakarta.

Widjaja, Gunawan, 2001, Rahasia Dagang, PT RajaGrafindo Persada, Jakarta.

Wijayanti, Asri, 2011, Strategi Penulisan Hukum, CV. Lubuk Agung, Bandung.

Yusran Isnaini, 2010, Buku Pintar HAKI, Ghalia Indonesia, Bogor.

Zainuddin Ali, 2016, Metode Penelitian Hukum, Cet.VII, Sinar Grafika, Jakarta.

\section{Jurnal}

Indira Swasti Gama Bhakti, 2017, "Rahasia Dagang dalam Usaha Franchise di Bidang Kuliner", Jurnal Fakultas Ilmu Sosial dan Ilmu Politik Universitas Tidar, Magelang.

\section{Peraturan Perundang-undangan}

Undang-Undang Republik Indonesia Nomor 30 Tahun 2000 tentang Rahasia Dagang (Lembaran Negara Republik Indonesia Tahun 2000 Nomor 242, Tambahan Lembaran Negara Republik Indonesia Nomor 4044).

Agreement on Trade-Related Aspects of Intellectual Property Rights.

Uniform Trade Secret Act with 1985 Amendments. 